\title{
Políticas de formação de professores para a Educação Profissional: cem anos de lutas
}

\author{
Maria Adélia da Costa ${ }^{1}$ \\ Antônio Meneses Filho ${ }^{2}$
}

\section{RESUMO}

Para alcançar o objetivo de apreender e problematizar as políticas para a formação de professores para a Educação Profissional (EP), sob o olhar da legislação brasileira entre 1917 e 2017, utilizou-se, como metodologia, a estratégia documental como fonte de dados. Foram acessados documentos legais, como o Decreto $n^{0}$ 7.566/1909, Resolução 06/2012 e a Lei $\mathrm{n}^{0}$ 13.415/2017. O marco temporal se justifica devido à criação da Escola Normal Artes e Ofícios Venceslau Brás, primeira a iniciar uma política de formação de professores para a EP, e à Lei 13.415/2017, que induz o "notório saber" aos profissionais dessa modalidade de ensino. Constata-se que a legislação apresenta flexibilidade quanto à formação de professores, consolidando os cursos emergenciais, fragmentados e especiais, o que pressupõe uma formação fragilizada, além de não evidenciar a obrigatoriedade da licenciatura.

PALAVRAS-CHAVE: Políticas públicas. Formação docente. Educação profissional.

Teacher training policies for vocational education: one hundred years of struggles

\begin{abstract}
Part of a master's research, documental and bibliographical in nature, this article aims to apprehend and problematize the policies for the formation of teachers for Professional Education (EP), under the Brazilian legislation from 1917 to 2017. This framework temporary is justified by the creation of the Venceslau Brás Normal School of Arts and Crafts, the first to initiate a policy of teacher training for PE, and Law
\end{abstract}

\footnotetext{
${ }^{1}$ Doutora em Educação, UFU. CEFET-MG, Belo Horizonte/MG. Brasil. adelia.cefetmg@ gmail.com.

${ }^{2}$ Mestre em Educação Tecnológica, CEFET-MG. IFMA. meneses.filho@ifma.edu.br
} 
13.415 / 2017, which induces "notorious knowledge" to professionals of this teaching modality. It is observed that the legislation presents flexibility regarding the training of teachers, consolidating the emergency, fragmented and special courses, which presupposes a weak formation, besides not evidencing the compulsory degree.

KEYWORDS: Public policy. Teacher training. Professional education.

$$
* * *
$$

\section{Introdução}

Este texto trata-se de um recorte de pesquisa desenvolvida no Programa de Pós-Graduação em Educação Tecnológica (PPGET), do CEFETMG. Tem por objetivo apreender e problematizar as políticas públicas (PPs) para a formação de professores para a Educação Profissional e Tecnológica (EPT), sob o olhar da legislação brasileira, entre 1917 a 2017.

A pesquisa científica exige um rigor na seleção de métodos e técnicas para a resolução do problema ou fenômeno. Segundo Apollinário (2009), as pesquisas possuem duas categorias de estratégias de coleta de dados:

a primeira refere-se ao local onde os dados são coletados (estratégia - local) e, neste item, há duas possibilidades: campo ou laboratório. [...] A segunda estratégia-se à fonte dos dados: documental ou campo. Sempre que uma pesquisa se utiliza apenas de fontes documentais (livros, revistas, documentos legais, arquivos em mídia eletrônica, diz-se que a pesquisa possui estratégia documental [...] (APOLLINÁRIO, 2009, p.85).

Considerando essas premissas, informa-se que nessa pesquisa utilizouse a estratégia documental como fonte de dados. Foram acessados documentos legais como o Decreto $\mathrm{n}^{0} 7.566 / 1909$, a Resolução CNE/CP $\mathrm{n}^{\circ}$ 6/2012 e a Lei $n^{\circ}$ 13.415/2017. Para a análise das normativas e legislações, recorreu-se à metodologia de análise do conteúdo, que se traduz por ser "um 
conjunto de técnicas de investigação científica utilizadas em ciências humanas, caracterizadas pela análise de dados linguísticos" [...] (APPOLINÁRIO, 2009, p. 27).

Busca-se, no decorrer deste texto, conectar os fios da trajetória histórica das políticas da formação de professores para a EPT com o atual contexto político-educacional, destacando a fragilidade dessas políticas públicas que, via de regra, são formatadas como programas de governo aligeirados e precarizados.

O cenário das PPs para a ensino na EPT, nos últimos cem anos, vem se constituindo por meio de normativas paliativas para regulação da ação docente nesta modalidade de oferta da educação básica. Isto é, existe uma ausência secular de políticas de $E_{\text {stado }}^{3}$, na materialização de legislaturas para a compreensão da docência como uma profissão que, assim como por exemplo, a medicina, a psicologia e o direito, requer uma formação específica para o desenvolvimento das atividades laborais.

Argumenta-se, neste texto, que a EPT, considerando a sua finalidade de formação humana e para o trabalho, é balizada pelo tripé cultura/política; ciência/tecnologia; e trabalho/educação. Desse modo, a educação profissional será compreendida na perspectiva da politecnia. Isto é, na ideia de que:

o processo de trabalho desenvolva, numa unidade indissolúvel, os aspectos manuais e intelectuais. Um pressuposto dessa concepção é de que não existe trabalho manual puro, e nem trabalho intelectual puro. Todo trabalho humano envolve a concomitância do exercício dos membros, das mãos, e do exercício mental, intelectual. Isso está na própria origem do entendimento da realidade humana, enquanto constituída pelo trabalho. Se o homem se constitui a partir do momento em que age sobre a natureza, adaptando-a a si, ajustando-a as suas necessidades (e ajustar às necessidades significa plasmar a matéria, a realidade,

\footnotetext{
3 As políticas de Estado são aquelas que envolvem mais de uma agência do Estado, passando em geral pelo Parlamento ou por instâncias diversas de discussão, resultando em mudanças de outras normas ou disposições preexistentes, com incidência em setores mais amplos da sociedade (OLIVEIRA, 2011, P.329).
} 
segundo uma intenção, segundo um objetivo, que é antecipado mentalmente), então o exercício da função intelectual já está presente nos trabalhos manuais os mais rudimentares, os mais primitivos. A separação dessas funções é produto histórico-social, separação esta que não é absoluta, é relativa (SAVIANI, 2003, p.138).

Entende-se que as ideias desse autor corroboram com a percepção de que a educação profissional é uma modalidade de ensino favorável ao desenvolvimento da concepção do processo de trabalho em sua unidade indissolúvel entre os aspectos manuais e intelectuais.

Diante disso, considera-se que a educação profissional requer políticas de formação docente que sejam capazes de consolidar os pares: cultura/política; ciência/tecnologia; e trabalho/educação, para que o profissional técnico de nível médio tenha uma formação que supere o reducionismo instrumental do aprendizado das técnicas, e tenha a oportunidade de reflexão crítica sobre os modos de produção e desenvolvimento societário.

\section{Escola Normal Venceslau Brás (1917) à Lei no 13.415/2017}

A primeira experiência de formação de professores para a educação profissional ocorreu, em 1917, na Escola Venceslau Brás. Tinha a finalidade de atender a necessidade de docentes nas Escolas de Aprendizes e Artífices, criadas por Nilo Peçanha, por meio do Decreto n ${ }^{0} 7.566$, em 1909. Contudo, essa formação foi efêmera, pois encerrou suas atividades 20 anos depois, em 1937.

Importa destacar que Constituição de 1891 consagrou que à União incumbiria a finalidade de criar instituições de ensino superior e secundário nos Estados. Contudo, somente em 1909 é que a educação profissional foi regulamentada sob a tutela da União. 
Portanto, foram quase 20 anos de silêncio e omissão do Estado (1891 1909). Essa experiência embrionária de formação profissional tem sua gênese marcada pelo viés assistencialista e balizada nos marcos da ascensão da ideologia liberal de base iluminista, cuja preocupação era abandonar o modelo assistencial das Casas de Educandos, incorporando a lógica de preparação para o trabalho, segundo Silva (2014).

Todavia, Cunha (1977), citado por Silva (2014), defende a ideia de que seria uma incoerência atrelar essas experiências de formação profissional como estratégias de educação para o trabalho, posto que não havia ainda um processo avançado de industrialização, o que aproximava as escolas de Aprendizes e Artífices mais a uma estratégia de controle social do que de preparação de força de trabalho para os modos de produção.

Se foi, a priori, uma estratégia para controle social, fato é que com o passar do tempo, a EPT foi sendo submetida a uma educação voltada a preparação de técnicos para ocupar postos de trabalho nas fábricas, indústrias, ou em outros lócus que necessitavam de mão de obra qualificada para o desenvolvimento das atividades laborais.

A criação da Escola Normal de Artes e Ofícios Venceslau Brás, em 1917, no antigo Distrito Federal, constituiu-se um marco histótico na implantação de política de formação de professores para o ensino industrial, pois, sua finalidade era a de formar os trabalhadores das indústrias e fábricas, provendo-os de uma formação para a docência, sobretudo, considerando que "os mestres de ofício vinham diretamente das fábricas, e seriam homens sem a necessária base teórica, a seu favor apenas a capacidade presumida de transmitir a seus discípulos os conhecimentos empíricos" (CUNHA, 2005, p. 80).

A incorporação dos mestres de ofício do mercado de trabalho para a atuação como professores no ensino técnico era um projeto, desde então, questionável, posto que a profissão docente envolve diferentes saberes ou conhecimentos, e que, portanto, não carece apenas do domínio técnico do conhecimento específico da profissão. Contudo, embora houvesse essa 
percepção, não foi realizada nenhuma ação política e estrutural para a publicação de normativas "obrigatórias" de formação docente para a atuação no ensino técnico.

Sobre os conhecimentos dos professores, Puentes et. al (2009), citando Shulman (1987), assevera que o "conhecimento base" para a docência requer qualidade e profundidade de compreensão, habilidades e capacidades, traços e sensibilidades. Estes aspectos integrados podem transformar uma pessoa em um professor competente. Shulman (1987) classifica em, no mínimo, sete as categorias da base de conhecimentos do professor:

1) conhecimento do conteúdo; 2) conhecimento pedagógico (conhecimento didático geral), tendo em conta, especialmente, aqueles princípios e estratégias gerais de condução e organização da aula, que transcendem o âmbito da disciplina; 3) conhecimento do currículum, considerado como um especial domínio dos materiais e os programas que servem como "ferramentas para o ofício" do docente; 4) conhecimento dos alunos e da aprendizagem; 5) conhecimento dos contextos educativos, que abarca desde o funcionamento do grupo ou da aula, a gestão e financiamento dos distritos escolares, até o caráter das comunidades e culturas; 6) conhecimento didático do conteúdo, destinado a essa especial amalgama entre matéria e pedagogia, que constitui uma esfera exclusiva dos professores, sua própria forma particular de compreensão profissional; 7) conhecimento dos objetivos, as finalidades e os valores educativos, e de seus fundamentos filosóficos e históricos (PUENTES, et. al, 2009, p. 173 apud SHULMAN, 2005, p. 11)

Isto é, sejam saberes ou conhecimentos, fato é que os professores necessitam de uma formação inicial em cursos de licenciaturas, sem, 
contudo, dispensar a formação em desenvolvimento, para que possam aprimorar o conhecimento base para a docência.

No que tange às normativas, o Decreto $n^{0} 13.064 / 1918$ determinava que as escolas de aprendizes artífices deveriam formar operários e contramestres, ministrando o ensino prático e desenvolvendo os conhecimentos técnicos, em oficinas de trabalho manual ou mecânico.

A determinação das habilitações profissionais deveria ser especificada pelas indústrias locais que ordenariam, conforme a sua necessidade de mão de obra qualificada, para atender a demanda dos serviços do momento. Isto é, a educação profissional estava, assim, subjugada à demanda do mercado, dos modos de produção. O fator determinante na escolha dos cursos a serem oferecidos a comunidade era a necessidade de ocupação dos postos de trabalho nas empresas locais.

No que tange à atividade docente, esse decreto determinava que, aos professores e mestres de oficinas competiam:

$1^{\mathrm{o}}$, comparecer à hora marcada para começo das aulas e oficinas e não se retirar antes de preenchido o tempo que devem durar as lições ou cursos a cargo de cada um; $2^{\circ}$, manter a disciplina na classe e fazer observar os preceitos de moral; $3^{\circ}$, prestar ao diretor todas as informações necessárias à boa ordem do serviço que for de sua atribuição; $4^{\circ}$, propor ao diretor o que for conveniente a boa marcha do ensino e a disciplina dos alunos; $5^{\circ}$, organizar, no último dia de cada mês, um mapa contendo o número de alunos matriculados, o número de dias letivos, o total dos comparecimentos, o total das faltas e a frequência média, a fim de ser enviada cópia a Diretoria Geral de Indústria e Comércio; $6^{\circ}$, apresentar ao diretor, no fim de cada trimestre, uma relação nominal dos alunos, com apreciação do comportamento, aplicação e aproveitamento de cada um. Art. 15. Os mestres de oficinas deverão ensinar a arte ou ofício a seu cargo em todos os seus 
detalhes, de modo que os aprendizes fiquem habilitados a executálos não só na oficina como fora dela (BRASIL, 1918, p. 01).

Entende-se, a partir do que foi exposto nesse decreto, que a atividade docente tinha a finalidade de colaborar no cumprimento do objetivo de subordinar a educação profissional ao mercado de trabalho, pois, as funções docentes estavam atreladas ao perfil de operário que interessava à indústria e ao comércio. Isto é, os professores deveriam se ater aos comportamentos morais, disciplinares e as habilidades técnico-profissionais desenvolvidas pelos alunos. O mapa de alunos e a descrição do perfil de cada um era submetido aos dirigentes da indústria e do comércio.

No período de 1917 a 1937, o número de matriculados, na Escola Normal Venceslau Brás, oscilava entre 122 e 459, preponderando o sexo feminino (CUNHA, 2005). Para Machado (2008a; 2008b), a Escola foi criada para formar dois tipos de professores: os mestres e contramestres para as escolas profissionais e as professoras, de trabalhos manuais para as escolas primárias. Contudo essa formação, em 1937, é interrompida, com o fechamento dessa instituição.

Durante os vinte anos de seu funcionamento, nesses dois cursos, foram 5.301 matrículas, ao todo. Mas chegaram até ao término dos dois cursos apenas 381 concluintes. Desses 381, 309 eram mulheres, provavelmente as professoras de trabalhos manuais para as escolas primárias, e apenas 72 homens. [...] coloco esse dado, [...] e acho muito interessante, porque já demonstra uma tendência de dar pouca importância à formação de professores para a educação profissional. Provavelmente, os 5.301 que se matricularam não sentiram muita necessidade de concluir um curso de formação pedagógica (MACHADO, 2008b, p. 68).

Machado (2008a), hipoteticamente, afirma que a Escola pode ter sido fechada, porque não correspondia mais o projeto inicialmente traçado: 
formar os mestres e contramestres para a indústria, uma vez que o público feminino predominou para o exercício nas escolas primárias.

Nessa direção, Brandão (1999) entende que a formação profissional passa a ter, na estrutura do aparelho de Estado, importância relacionada à necessidade crescente de formação de mão-de-obra para a então incipiente indústria, uma vez que não se pretendia iludir ninguém quanto às possibilidades daquele ensino, ou seja, de que não se pretendia formar 'doutores'. Esse projeto foi recepcionado pelo Decreto n ${ }^{\circ} 4.073 / 1942$, que institui a formação de professores para o Ensino Industrial, porém sem materialidade importante no que diz respeito à formação (MACHADO, 2008a).

\section{A formação de professores na primeira Lei de Diretrizes e Bases brasileira}

Em 1961, a Lei de Diretrizes e Bases (LDB), $\mathrm{n}^{\circ} 4.024$, no que tange à formação de professores para a EPT, apresenta uma dualidade formativa quanto aos lócus de fomento. Para o exercício das disciplinas do ensino técnico, os graduados não licenciados devem fazer cursos especiais de educação técnica e para o exercício do magistério no ensino médio, os lócus de fomento eram as faculdades de filosofia, ciências e letras (MACHADO, 2008a), o que consagra a distinção entre os professores das disciplinas técnicas e os demais, reforçando "a legitimidade de dois percursos formativos distintos de formação docente: o 'acadêmico' e o 'técnico', este de menor valia” (OLIVEIRA, M., 2011, p. 201).

Além de separar formalmente os lugares da formação de professores para o ensino médio e da formação de professores das disciplinas específicas do ensino técnico, essa normativa reforça o tratamento diferenciado e de curso especial, "de forma que até hoje a referência mais forte que se tem é a de que a formação docente para a educação profissional deve se dar em cursos especiais" (FRANCO, 2008, p. 70). 
A Lei $\mathrm{n}^{\circ} 5.540 / 68 \mathrm{~L}$, que institui a Reforma Universitária, exige-se que a formação de todos os professores do ensino de segundo grau, tanto às disciplinas gerais quanto às técnicas, deve dar-se em nível superior. Porém, essa exigência foi "logo em seguida relaxada" (MACHADO, 2008a, p. 11), porque:

Essa exigência, entretanto, foi flexibilizada já no ano seguinte pelo Decreto-lei no 464/69, que instrui normas complementares à Lei ${ }^{\circ}$ 5.540/1968. No seu art. 16, esse decreto determinou que, enquanto não houvesse número suficiente de professores e especialistas formados em nível superior, a habilitação para a docência no ensino técnico poderia ser feira mediante exame de suficiência realizado em intuições oficiais de ensino superior indicados pelo Conselho Federal de Educação (FRANCO, 2008, p. 72).

A Portaria Ministerial 339/70 institui os Esquemas I e II. Em relação esses programas emergenciais, toma-se a acepção em Lima (2013), para quem:

Os chamados Cursos Emergenciais Esquema I e Esquema II traziam suas peculiaridades: o primeiro trazia o objetivo de possibilitar a formação pedagógica aos portadores de diploma de nível superior; o segundo trazia essa mesma formação do Esquema I aos portadores de diploma de técnico, além de acrescentar as disciplinas de conteúdo técnico específico. Ou seja, no Esquema I, permite-se que qualquer profissional formado com graduação de nível superior possa obter sua formação pedagógica, cursando as disciplinas pedagógicas, exigidas para as licenciaturas. Ele passa a ter autorização para lecionar no ensino de $2^{\circ}$ grau. Já no Esquema II, qualquer profissional formado em nível médio técnico que curse, além das disciplinas pedagógicas, disciplinas de conteúdo específicos relativos à área de seu diploma de segundo grau, passa a fazer jus aos direitos dos licenciados (LIMA, 2013, p.87). 
Em 1977, por meio da Resolução n ${ }^{\circ}$ 3, do Conselho Federal de Educação (CFE), instituiu-se a licenciatura plena, para a parte da formação especial do $2^{\mathrm{o}}$ grau, fixando o currículo mínimo e determinando às instituições a oferta dos Esquemas I e II, de modo a adequá-los em licenciaturas, dentro de três anos (MACHADO, 2008a; FRANCO, 2008).

\section{Os Centros Federais de Educação Tecnológica e as licenciaturas}

Em 1978, a transformação das Escolas Técnica Federais de Minas Gerais, do Paraná e do Rio de Janeiro, em Centros Federais de Educação Tecnológica (CEFETs), por meio da Lei $\mathrm{n}^{\mathrm{o}}$ 6. 545/78, significou uma mudança significativa em relação ao percurso formativo no âmbito dessas "novas" instituições, posto que preconizava que essas instituições teriam por finalidade o oferecimento de educação tecnológica e por objetivos:

I - ministrar em grau superior: a) de graduação e pós-graduação lato sensu e stricto sensu, visando à formação de profissionais e especialistas na área tecnológica; b) de licenciatura com vistas à formação de professores especializados para as disciplinas específicas do ensino técnico e tecnológico; II - ministrar cursos técnicos, em nível de $2^{\circ}$ grau, visando à formação de técnicos, instrutores e auxiliares de nível médio; III - ministrar cursos de educação continuada visando à atualização e ao aperfeiçoamento de profissionais na área tecnológica; IV - realizar pesquisas aplicadas na área tecnológica, estimulando atividades criadoras e estendendo seus benefícios à comunidade mediante cursos e serviços (BRASIL, 1978).

Vale ressaltar que o objetivo determinado na supracitada lei é referente à formação de professores para as disciplinas específicas do ensino técnico e tecnológico. Ou seja, o foco era formar professores para as áreas 
técnicas. Contudo, os professores da Base Nacional Comum (BNC) também careciam e carecem de serem formados para a educação profissional, pois, as licenciaturas tendem a habilitar os docentes para o ensino fundamental e médio, excluindo assim as discussões e problematizações peculiares da EPT.

Entende-se que essa iniciativa, formação professores para as áreas técnicas, foi um marco considerado relevante na particularidade da elaboração de políticas públicas para a formação de professores para a educação profissional.

Não obstante, apesar da determinação da referida lei, o CEFET-MG, a partir de 1981, deixou de ofertar as licenciaturas e passou a oferecer o programa especial de formação pedagógica para docentes (PEFPD) (CEFETMG, PDI, 2015). O CEFET-RJ, além dos cursos de nível médio e nível técnico, cursos de graduação, voltados para a Engenharia, ainda se incumbiu da formação de professores para as disciplinas de cultura técnica, bem como a licenciatura em física (CEFET-RJ, PDI, 2017).

Considera-se que as instituições de educação profissional como, por exemplo, os CEFETs que têm em sua gênese a oferta do ensino técnico de nível médio (ETNM), tenham a sensatez de inserir nos projetos de cursos de licenciatura, disciplinas que possam corroborar com a docência na EPT, independentemente se a habilitação do aluno-professorando será em áreas técnicas ou de formação geral.

Esse pressuposto baliza-se no entendimento que a EPT tem suas especificidades e temas como, por exemplo, educação, trabalho, cultura, ciência e tecnologia, não podem estar a margem das discussões e debates em salas de aula que estão formando professores e, sobretudo, por se constituírem historicamente como lócus de formação de profissionais para o mercado de trabalho (COSTA, 2016).

Com efeito, partindo dessa premissa, verificou-se que a licenciatura em física do CEFET-RJ, não tem em seu projeto pedagógico ou de curso indícios que possam induzir a formação de professores de física para EPT. Isto porque as disciplinas que poderiam fazer essa ponte, como é o caso de 
"fundamentos da educação" e "política educacional e formação de professores no Brasil", não se referem em suas ementas a nenhuma aproximação com a EPT.

Quanto ao CEFET-PR, que se transformou na única Universidade Tecnológica Federal do país (UTFPR), além de ofertar cursos de licenciaturas, oferta, também, cursos lato sensu em formação pedagógica, como Educação: Métodos e Técnicas de Ensino; Inovação e Tecnologias na Educação; e Tecnologias, Comunicação e Técnicas de Ensino (UTFPR, 2018).

Isto posto, a criação das licenciaturas nos CEFETs, em 1978, provocou apreensões e muitas consultas ao CFE, por parte dos professores formados pelos Esquemas I e II que receosos queriam saber sobre as chances que teriam de continuar no exercício da docência, uma vez que se instruía a licenciatura nessas instituições públicas federais (FRANCO, 2008, p. 77). Isso devido à escassez de professores em nível superior. Percebe-se que a licenciatura, como formação inicial, constitui-se o fosso para a EPT, possibilitando, por meio de cursos emergenciais, "suprir" uma lacuna no percurso formativo do professor para essa modalidade educacional.

\section{A atual LDB e a docência para a EPT}

Em 1996, a $\operatorname{LDB}^{\circ} 9.394$ instituiu as diretrizes gerais para a formação de professores, contudo, não houve a obrigatoriedade da formação em curos de licenciaturas para a EPT (COSTA, 2016; MACHADO, 2008a), nem tampouco a educação profissional foi incorporada a educação básica. Esse tratamento torna-se mais evidente, no Art. 62, que regulamenta a formação de docentes para atuar na educação básica (na origem dessa LDB, a educação profissional não era componente da educação básica.

Somente em 2008, por meio da lei $\mathrm{n}^{0}$ 11.741, a EP passa a ser considerada uma modalidade da educação básica), que exige que a formação de professores para atuar na educação básica seja de nível superior, em curso de licenciatura, de graduação plena. 
A rigor, expressa-se a obrigatoriedade da licenciatura como formação inicial para a Educação Básica (EB), como amparo legal para o exercício do magistério. No entanto, para a formação de professores para a EPT, não institui a obrigatoriedade da licenciatura como formação inicial para o professor desse campo, o que ratifica o "não reconhecimento da docência na EP como um campo de conhecimento com identidade própria" (OLIVEIRA M., 2010, p. 202). O que implica em uma contradição.

Desse modo, entende-se que ao não se referir, explicitamente, ao professor para a educação profissional, "a lei viabiliza a interpretação de que o docente da área não carece de uma formação própria, mesmo para o caso do ensino técnico de nível médio. Alia-se a isso dada concepção sobre as relações entre a experiência profissional e a formação acadêmica na EPT como campo de conhecimento com identidade própria” (BURNIER; OLIVEIRA, 2013, p. 159-160).

Por meio do Decreto $\mathrm{n}^{\circ}$ 2.208/97, mais uma vez a formação de professores para a EPT "não carece de especificidade, quando se estabelece em seu artigo $9^{\circ}$ que as disciplinas do ensino técnico 'serão ministradas por professores, instrutores e monitores selecionados, principalmente em função de sua experiência profissional” (PENA, 2014, p. 63). Para Costa (2016), a promulgação desse decreto está na contramão dos pressupostos de uma formação integrada do sujeito e das lutas sociais, além de ser marcado historicamente pela representação da ruptura da EPT, ao se proibir a integração do ensino médio e o ensino técnico.

Em 1997, o Conselho Nacional de Educação (CNE), por meio da Resolução $n^{\circ} 2 / 97$, institui programas especiais de formação pedagógica, sem promover a discussão sobre a alternativa de cursos de licenciatura (MACHADO, 2008a; OLIVEIRA M., 2008, 2011; COSTA, 2016).

Para Costa (2016), essa resolução se reveste de uma velha regulamentação promovida pelos Esquemas I e II. “Ou seja, essa resolução é uma versão maquiada desses esquemas que objetiva especificamente a supressão da lacuna de professores habilitados para determinadas 
disciplinas, como por exemplo, matemática e física, e em determinadas regiões do País" (COSTA, 2016, p. 85).

Em 2004, a promulgação do Decreto n. 5.154/2004, que revogou o 2.208/1977, possibilitou a retomada do Ensino Médio Integrado (EMI), o que traz à tona a concepção da politecnia e omnilateralidade, que, segundo Frigotto, Ciavatta e Ramos (2005, p.22), “[...] permite romper com as amarras da dependência e subordinação externa e deixar de ser um 'país gigante com pés de barro"'. Isso tem representado "um avanço para a EPT, ao possibilitar a educação profissional integrada" (COSTA, 2016, p.91), embora esse decreto não tenha rompido com o dualismo educacional historicamente presente na educação do Brasil. E sem concretização de uma formação de professores para a EPT.

Em 2012, a Resolução CNE/CP n 6 instituiu as diretrizes curriculares nacionais para a Educação Profissional Técnica de Nível Médio (EPTNM), "estabelecendo orientações para a formação docente, contudo mantêm a ambiguidade no que se refere a essa questão" (PENA, 2014, p. 72). Ou seja, sem prevê a obrigatoriedade da licenciatura (COSTA, 2016; MACHADO, 2008a; OLIVEIRA B., 2016).

Essa resolução, no art. 40, deixa claro que a formação inicial para essa área se realiza em cursos de graduação e programas de licenciatura ou outras formas, consoante à legislação e com normas específicas definidas pelo CNE, ratificando a não obrigatoriedade da licenciatura como habilitação necessária ao exercício da docência.

Para Costa (2016), com essa normativa, as diretrizes não mudam o cenário no que tange à formação de professores, pois se constitui fragilizada, já que:

Garantir o direito não é suficiente à medida que fica a critério de o profissional aceitar ou não esse direito. Ter o direito de se tornar professor não é o mesmo que ter obrigatoriedade de ser professor para que possa lecionar na Educação Profissional Técnica de Nível 
Médio. No meu entendimento essa resolução não configura avanço à medida que apenas possibilita e regulamenta outros modos de se tornar docente sem necessariamente cursar licenciatura ou programas de formação pedagógica (COSTA, 2016, p. 204).

A instituição da RFEPCT e a criação dos IFs, por meio da Lei da 11.892/2008, estabeleceu que essas instituições teriam, a partir de então, a competência de ofertar cursos de formação de professores, em geral, e também para a EPT, cujos lócus são adjetivados como especializados, diferenciados (COSTA, 2016; BURNIER; OLIVEIRA, 2013; LIMA, 2013; 2014; OLIVEIRA B., 2016; PENA, 2014), e, segundo a normativa, a oferta é de, no mínimo, 20\% das vagas para os cursos de licenciaturas.

Com a promulgação da Lei $n^{0} 11.741 / 2008$, que alterou os dispositivos da Lei n 9.394/1996, entende-se que a EPT é uma modalidade da EB, explícita na legislação brasileira, que "sem prejuízo do disposto na Seção IV deste Capítulo, o ensino médio, atendida a formação geral do educando, poderá prepará-lo para o exercício de profissões técnicas" (BRASIL, 1996). Contudo, a separação da EPT da EB "é reflexo e consequência da LDB n. 9.394/1996, que não considerava a educação profissional parte da educação básica” (COSTA, 2016, p. 246) e vê que essa desarticulação é compreendida "como um ranço do desmantelamento posto pela própria LDB e pelo decreto n. 2.208/1997 (COSTA, 2016, p. 246).

Essa concepção de EB trazida por essa lei à LDB representou, no ver de Kuenzer (2010), uma mudança significativa para a educação brasileira, no sentido de democratizar a oferta de educação pública de qualidade a toda população, e, particularmente, aos que só têm na instituição pública o espaço de acesso ao conhecimento e à aprendizagem do trabalho intelectual, assegurando

a integração entre os diferentes níveis e modalidades de ensino, de modo a propiciar a todo e qualquer cidadão, respeitando a 
diversidade, a formação considerada como o mínimo necessário à participação na vida social e produtiva. É a concepção de educação básica que assegura a organicidade da Educação Nacional, através do princípio da integração: - dos níveis: a educação infantil, o ensino fundamental e o ensino médio; - das modalidades: educação profissional, educação do campo, educação especial, educação de jovens e adultos, educação indígena (KUENZER, 2010, p.501).

Dessa forma, a EP passa a ser compreendida como modalidade integrante da EB; "assim, não há como conceber a formação de professores para esta modalidade senão como integrada à formação de professores para a educação básica, o que significa formação superior em nível de licenciatura" (KUENZER, 2010, p. 502). Assim sendo, a formação de professores para a EP deve ter a mesma base comum de formação pedagógica que deverão ter os demais professores da EB, focalizando-se na articulação entre ciência, trabalho e cultura.

Em 2015, a Resolução $n^{0}$ 02/2015 regulamenta os cursos de licenciatura, os cursos de formação pedagógica para graduados e os cursos de segunda licenciatura para os docentes da EB, novamente adjetivando-os de emergenciais e especiais, sem materializar políticas perenes de formação docente (COSTA, 2016). Em sua pesquisa de mestrado, Oliveira, B. (2016) problematiza a formação de professores para a educação profissional, sob o olhar dos seguintes documentos legais: Resolução $n^{\circ}$ 02/1977; Lei 11.741/2008; Decreto n. 6.755/2009 (Institui a Política Nacional de Formação de Profissionais do Magistério da Educação Básica (PARFOR); Resolução no 02/2012; Lei 12.772/2012 (Institui a carreira do magistério do Ensino Básico, Técnico e Tecnológico (EBTT); Lei n ${ }^{\circ}$ 13.005/2014 (Aprova o Plano Nacional de Educação (PNE)); Resolução nº 02/2015, além da LDB nº 9.194/1996.

A pesquisadora constata que, em relação à formação inicial de professores para a EP, houve um avanço, porém, “mantém-se o que tem sido a norma geral para essa formação, tal como historicamente definida. Ou seja, suposta flexibilidade por meio de uma gama de possibilidades, mas que 
acabam por implicar uma formação diferenciada e aligeirada" (OLIVEIRA, B., 2016, p. 52).

Essa flexibilidade é legitimada por meio da Lei $\mathrm{n}^{0}$ 13.415/ 2017, do atual governo brasileiro, Michel Temer, a qual institui o "novo" Ensino Médio. Para atuarem na EPT, quaisquer profissionais, com "notório saber", se habilitam. A normativa traz categoricamente essa concepção no art. $6^{\circ}$, inciso IV:

[...] profissionais com notório saber reconhecido pelos respectivos sistemas de ensino, para ministrar conteúdos de áreas afins à sua formação ou experiência profissional, atestados por titulação específica ou prática de ensino em unidades educacionais da rede pública ou privada ou das corporações privadas em que tenham atuado, exclusivamente para atender ao inciso $\mathrm{V}$ do caput do art. 36 (BRASIL, 2017).

O Grupo de Trabalho (GT), de Política Educacional da Universidade de São Paulo (USP), ao problematizar esse artigo, do notório saber, o qual a Lei 13.415/2017, induz a "possibilidade de pessoas não formadas nas licenciaturas assumirem funções docentes. Seguindo velhos hábitos brasileiros, qualquer profissional graduado, apenas com uma complementação pedagógica, poderá assumir aulas no novo ensino médio". Portanto, entende-se que existe a possibilidade de a profissão-professor voltar a ser um bico, aviltando mais as já insuficientes remunerações dos professores de grande parte das redes públicas (USP, 2017).

Nos ditames da legislação, para atuar na EB regular, reforça-se a exigência da formação docente em nível superior, em curso de licenciatura plena, "admitida, como formação mínima para o exercício do magistério na educação infantil e nos cinco primeiros anos do ensino fundamental, a oferecida em nível médio, na modalidade normal” (BRASIL, 2017), cuja concepção se apresenta contraditória, já que a EPT também é parte da EB, o que constitui mais um retrocesso. 
Oliveira, M. (2008), contribui com essas ideias, sobretudo, ao considerar que a formação de professores do ensino técnico "vem sendo tratada como algo especial, emergencial, sem integralidade própria, que carece de marco regulatório (...). Evidencia uma situação de faltas de/na formação o que, justifica-se pelo recorrente não reconhecimento de um saber sistematizado da área" (OLIVEIRA, M., 2008, p. 168).

Considera-se que a supracitada lei, que (de)forma o ensino médio, ratifica o projeto de interesse de um determinado grupo societário, evidenciado na década de 1990: uma política neoliberal, de cunho mercantilista, regulado pelo capital, "à medida que possibilita a formação de força de trabalho para as necessidades desse mercado" (COSTA, 2016, p. 68). Essa política neoliberal reforça mais ainda a "inclusão excludente" para/na EPT, e a "exclusão includente", para/no mundo do trabalho, apropriando-se da expressão de Kuenzer (2008; 2010).

$\mathrm{Na}$ particularidade do cenário atual, em que foi publicada a lei $\mathrm{n}^{\circ}$ 13.415/2017, que possibilita aos profissionais com notório saber ministrar conteúdos de áreas afins à sua formação ou experiência profissional, exclusivamente para atender ao ensino técnico, entende-se que as políticas de formação de professores para a EPT retrocedem um século, o que por conseguinte, condiciona a profissão professor da EPT a permanecer no status periférico e precário do sistema educacional brasileiro.

Essa lei ignora que a profissão docente tem suas especificidades e que uma sala de aula não é um grupo de pessoas escolhidas em razão de suas afinidades. Não é, tampouco, um conjunto de pessoas que compartilham convicções ideológicas ou religiosas (...). É um espaço e um tempo estruturados por um projeto específico que alia ao mesmo tempo e indissociavelmente a transmissão de conhecimentos e a formação dos cidadãos (MEIRIEU, 2006, p.68).

Portanto, para atuar nesse espaço, exige-se mais que um saber reconhecido como notório. Requer uma formação que inclua, além de questões didático-político-pedagógicas, a discussão relativa à função social 
da EPT, bem como o entendimento sobre o papel do docente na formação do técnico/trabalhador, o qual, evidentemente, não pode mais ser o de quem apenas ministra aulas e transmite conteúdos, repetindo exemplos para a memorização dos estudantes (MOURA, 2008, p.35).

Nesse sentido, entende-se que a lei $n^{0}$ 13.415/2017 induz a dualidade educacional ao privilegiar o saber da prática em detrimento das dimensões sociopolítico, cultural, didático-pedagógico. E ainda, reafirma-se a tendência de ratificar a condição de desprestígio da profissão/professor.

\section{Considerações Finais}

O presente artigo teve o objetivo de apreender e problematizar as políticas públicas para a formação de professores para a EPT, sob o olhar da legislação brasileira entre 1917 a 2017. Observou-se que há uma ausência do Estado em regulamentar políticas perenes para a docência na EPT. Desse modo, a formação de professores para a EPT, materializada nos documentos legais, evidencia um descaso histórico, de mais de cem anos, com a profissão professor da EPT, induzindo que todo profissional graduado, bacharel ou tecnólogo, poderá exercer essa profissão, sem, contudo, se formar em cursos de licenciaturas.

É manifesto o não interesse do Estado em regulamentar políticas de formação de professores para a EPT, uma vez que, para atuar nesse campo educacional, basta o conhecimento técnico-científico do graduado sem licenciatura, o que é confirmado também pela recente Lei 13.415, cujo conhecimento se restringe ao "notório saber". Não necessita, portanto, no ver da legislação, da licenciatura como formação inicial.

As discussões e debates sobre a formação de professores para a EPT ganham evidência sobretudo em setembro de 2006, embora três anos antes já se haviam suscitadas discussões, em eventos e fóruns de educação, objetivando materializar políticas de formação para esse campo educacional, 
sobretudo no que tange à obrigatoriedade da licenciatura como formação inicial para o exercício da docência.

Contudo, nesses cem anos de árdua trajetória política-formativa, ainda não se efetivou nenhuma ação de erradicação dessa condição precária em que se situa a formação de professores para a EPT, o que torna claro o jogo de interesses de grupos societários que estão no poder, de modo atender ao capital, subjugando a formação profissional aos desmandos do mercado de trabalho.

Da Escola Normal em 1917 à Lei 13.415/2017, o lapso temporal é diferente, porém, as políticas para esse campo, no lapso de 100 anos, continuam as mesmas: mais retrocessos, que "avanços", o que implica contradições. Entende-se, portanto, que as pesquisas na área devem ser contínuas, de modo que as vozes nos foruns e/ou eventos de educação sejam ouvidas para, de fato, obstruírem políticas de formação aligeiradas, emergenciais, provisórias, especiais, e materializarem políticas perenes.

Enquanto não houver uma materialidade dessas políticas, outros "meios" são vistos na legislação como uma "solução" para a formação de professores na EPT, conforme evidenciado pelo percurso histórico aqui estabelecido (1917-2017).

\section{Referências}

APPOLINÁRIO, F. Dicionário de metodologia científica: um guia para a produção do conhecimento científico. São Paulo: Atlas, 2009.

BRANDÃO, M. Da Arte do Ofício à Ciência da Indústria: a conformação do capitalismo industrial no Brasil vista através da educação profissional. Boletim Técnico do SENAC, Rio de Janeiro, v. 25, n. 3, p. 17-30, set./dez. 1999.

BRASIL. Decreto $\mathrm{n}^{\circ}$ 13.064, de 12 de junho de 1918. Dá novo regulamento ás Escolas de Aprendizes Artífices. Brasília, 1918. Disponível em: $<$ http://www2.camara.leg.br/legin/fed/decret/1910-1919/decreto-13064-12-junho1918-499074-republicacao-95621-pe.html>. Acesso em 14 mar. 2017. 
. Lei n. 9.394, de 20 de dezembro de 1996. Estabelece as diretrizes e bases da educação nacional. Brasília: MEC/SEF, 1996. Disponível em <http://www.planalto.gov.br/ccivil_03/Leis/L9394.htm.> Acesso em 11 mai. 2017.

. Lei n. ${ }^{\circ}$ 11. 892, de 29 de setembro de 2008. Brasília, 2008a. Disponível em $<$ http://www.planalto.gov.br/ccivil_03/_ato2007-2010/2008/lei/l11892.htm>. Acesso em 07 mar.2016.

. Lei n. 11.741, de 16 julho de 2008. Brasília: MEC, 2008b. Disponível em: $<\mathrm{http}$ ///www.planalto.gov.br/ccivil_03/_Ato2007-2010/2008/Lei/L11741.htm> Acesso em: 07 mar. 2016.

$2012 \mathrm{a}$.

Resolução CNE/CEB n. 6, de 20 de setembro de 2012. Brasília: MEC, http://portal.mec.gov.br/index.php?option=com_content\&id=17417\&Itemid=866>. Acesso em 07 mai. 2017.

Disponível

Resolução CNE/CP n. 2, de $1^{\circ}$ de julho de 2015. Brasília: MEC, 2015. http://portal.mec.gov.br/index.php?option $=$ com docman\&view $=$ download\&alias $=17$ 719-res-cne-cp-002-03072015\&category_slug=julho-2015-pdf\&Itemid=30192>. Acesso em 07 mai. 2017.

Lei $\mathrm{n}^{\circ}$ 13.415, de 16 de fevereiro de 2017. Brasília, 2017. Disponível em: < http://www.planalto.gov.br/ccivil_03/_ato2015-2018/2017/lei/L13415.htm>. Acesso em: 23 mai. 2017.

COSTA, M. A. da. Políticas de formação de professores para a educação profissional. realidade ou utopia. Curitiba: Appris, 2016.

CUNHA, Luiz Antonio. O ensino de ofício nos primórdios da industrialização. São Paulo: Editora UNESP, 2005.

FRANCO, M. C. Formação de professores para a educação profissional e tecnológica: perspectivas históricas e desafios contemporâneos. In: Educação Superior em Debate: Formação de Professores para Educação Profissional e Tecnológica. Brasília: INEP, 2008.

FRIGOTTO, G.; CIAVATTA, M.; RAMOS, M. A gênese do Decreto n. 5.154/2004: um debate no contexto da democracia restrita. In: FRIGOTTO, G; CIAVATTA; M.; RAMOS, M. (Orgs.). Ensino médio integrado: concepções e contradições. São Paulo: Cortez, 2012.

LIMA, F. B. G. de. A formação de professores nos Institutos Federais: perfil da oferta. In: Revista EIXO, Brasília, DF, v. 2, n. 1, p. 83-105, jan./jun. 2013. Disponível em: http://revistaeixo.ifb.edu.br/index.php/RevistaEixo/article/view/104/52. Acesso em: 12 mar. 2017. 
A formação de professores nos institutos federais de educação, ciência e tecnologia: um estudo da concepção política. Natal: IFRN, 2014.

KUENZER, A. Z. Formação de professores para a educação profissional e tecnológica. In: DALBEN, Â. I. Lo.o de F. [et. al.]. Convergências e tensões no campo de formação e do trabalho docente. Belo Horizonte: Autêntica, 2010.

Formação de professores para a educação profissional e tecnológica: perspectivas históricas e desafios contemporâneos. In: Educação Superior em Debate: Formação de Professores para Educação Profissional e Tecnológica. Brasília: INEP, 2008.

MACHADO, L. R. S. Diferenciais inovadores na formação de professores para a educação profissional. In: Revista Brasileira da Educação Profissional e Tecnológica. V. 1, n. 1, (jun. 2008). Brasília: MEC, SETEC, 2008a, p. 8-22. Disponível em: < http://portal.mec.gov.br/setec/arquivos/pdf3/rev_brasileira.pdf>. Acesso em: 22 mai. 2017.

Formação de professores para a educação profissional e tecnológica: perspectivas históricas e desafios contemporâneos. In: Educação Superior em Debate: Formação de Professores para Educação Profissional e Tecnológica. Brasília: INEP, 2008b.

MEIRIEU, P. Carta a um jovem professor. Porto Alegre: Artmed, 2006.

MOURA, D. H. A formação de docentes para a educação profissional e tecnológica. In: Revista Brasileira da Educação Profissional e Tecnológica. V. 1, n. 1, (jun. 2008). Brasília: MEC, SETEC, 2008. Disponível em: < http://portal.mec.gov.br/setec/arquivos/pdf3/rev_brasileira.pdf>. Acesso em: 22 mai. 2017.

OLIVEIRA, Maria Rita Neto Sales. Formação de professores para educação profissional. In: OLIVEIRA, D.A.; DUARTE, A.M.C; VIEIRA, L.M.F. DICIONARIO: trabalho, profissão e condição docente. Belo Horizonte: UFMG/Faculdade de Educação, 2010. CD-ROM.

A formação de professores para a educação profissional técnica de nível médio. In: PINHO, Sheila Zambello de. (Orgs). Formação de professores: dilemas contemporâneos. São Paulo: Editora Unesp, 2011.

OLIVEIRA, M. R. N. S.; BURNIER, S. L. Perfil das licenciaturas nos institutos federais de educação, ciência e tecnologia. In: Formação/profissionalização de professores e formação profissional e tecnológica: fundamentos e reflexões contemporâneas. Belo Horizonte: PUC Minas, 2013.

OLIVEIRA, D. A. Das políticas de governo à política de estado: reflexões sobre a atual agenda educacional brasileira. Educação e Sociedade, Campinas, v. 32, n. 115, p. 323-337, abr.-jun. 2011. Disponível em: http://www.scielo.br/pdf/es/v32n115/v32n115a05.pdf. Acesso em 18 nov. 2018. 
PENA, G. Docência na Educação Profissional e Tecnológica: conhecimentos, práticas e desafios de professores de cursos técnicos na Rede Federal. Tese (Doutorado em Educação). Faculdade de Educação, Universidade Federal de Minas Gerais. Belo Horizonte: UFMG, 2014.

PUENTES, R. V.; AQUINO, O. F.; NETO, A. Q. Profissionalização dos professores: conhecimentos, saberes e competências necessários à docência. Educar, Curitiba, n. 34, p. 169-184, 2009.

SAVIANI, Dermeval. O choque teórico da politecnia. Trabalho, Educação e Saúde, 1(1):131-152, 2003. Disponível em: http://www.scielo.br/pdf/tes/v1n1/10.pdf. Acesso em: 04 nov. 2018.

SILVA, L. C. da. A entrada dos trabalhadores nos institutos federais pela via dos cursos de formação inicial e continuada: uma análise sobre a educação dos mais pobres. Tese apresentada ao Programa de Pós-graduação em Educação da Universidade Federal Fluminense para a obtenção do título de Doutora em Educação. Campo de Confluência: Trabalho e Educação. Rio de Janeiro: UFF, 2014.

USP. A quem interessa a reforma do Ensino Médio do Governo Temer? Grupo de Trabalho de Política Educacional. São Paulo: USP, 2017. Disponível em: http://www.adunesp.org.br/atx/arquivos/arqAdunesp--15-03-2017--

58c94c1517b77.pdf. Acesso em: 01 jun. 2017.

UTFPR. Cursos. Curitiba: UTFPR, 2018 Disponível em: http://portal.utfpr.edu.br/cursos/especializacao\#b_start=0\&c4=educa\%C3\%A7\%C3 \%A3o. Acesso em: 06 nov. 2018. 